\title{
Personal Identity and Self-Regarding Choice in Medical Ethics
}

Lucie White

This is a preprint of a book chapter - the published version can be found in: M. Kühler and V. Mitrović (eds.), Theories of the Self and Autonomy in Medical Ethics, Switzerland: Springer, 2020, pp. 31-47.

\section{Introduction}

Philosophical concerns with personal identity have long formed a central part of debate on certain bioethical issues such as abortion (McInerney 1990; Oderberg 1997; Warren 1977) and advance directives (Buchanan 1988; DeGrazia 1999). But these considerations have received renewed attention in the context of the personality changes potentially induced by deep brain stimulation (Jecker and Ko 2017; Müller, Bittlinger and Walter 2017; Nyholm and O’Neill 2016). The focus of this paper is to point out some problems that arise in some of these recent discussions of personal identity and medical ethics - particularly, when it comes to understanding the importance of respecting self-regarding choice in medical contexts. It is widely agreed that it is very important to respect a patient's self-regarding decisions in medical ethics. I argue that once we delve into this, we will see that some of the value we place on making our own decisions relies on an assumption that is central to a particular picture of personal identity - that we will remain psychologically connected to our future selves to an adequate degree. Recognising this doesn't require us to make any metaphysical claims about what a person is through time. But work in medical ethics based on non-psychological theories of personal identity run into problems insofar as it is unable to recognise the importance of psychological connectedness.

I will draw this out as follows: first, I will delve into the moral basis for according so much importance to respecting self-regarding decisions in medical ethics, with the help of work from T.M. Scanlon. I will look at the various reasons that we generally value making our own choices, showing that part of the reason we value making choices with a significant, long-term impact relies on an underlying assumption that the agent making the decision will be psychologically connected to her future self to an adequate degree (Section 2). Although a focus on psychological connectedness is the basis of a psychological or neo-Lockean theory of personal identity, I will argue that we don't have to make any metaphysical commitment about what the "self' is through time to recognise the importance of psychological connectedness as the basis for self-regarding decisions. I will situate this in a more general account connecting the reasons we have to value 
making our own choices with concerns typically discussed in the context of personal identity (Section 3).

With this in hand, I will turn to two treatments of personal identity in connection with medical ethics, which, I will argue, run into problems due to a failure to recognise the importance of psychological connectedness. First, I will look at a discussion of advance directives, and how personality changes might impact their authority. I will argue that the moral authority of advance directives is unavoidably based, in part, on an assumption of psychological connectedness. I will show that this comes apart from metaphysical questions about personal identity, and that it can explain our reaction to certain difficult cases. I will argue that this recognition doesn't require us to abandon advance directives where psychological connectedness is disrupted (they may be justified on other grounds) but that we have to recognise the relevance of psychological connectedness to questions about the value of advance directives and the circumstances under which they should hold (Section 4).

I will then turn to a rather different problem - the problem of making medical decisions that may involve drastic psychological change, brought on by deep brain stimulation. I will argue that without an underlying basis of psychological connectedness motivating our decisions and delineating what counts as wanted (or unwanted) personality change, we have no basis upon which decisions can be made. This means that we cannot capture or understand what is of concern to the patient when she expresses fear or reservations about personality change brought on by DBS. I will show that psychological connectedness does not require that the psychological attributes of the person remain static through time - certain changes are compatible with psychological connectedness (Section 5). These two cases show that we can't completely understand the value of making self-regarding decisions over time, and thus the source of authority of these decisions, and what is of concern to the patient when making these decisions, without engaging with considerations of psychological connectedness. Psychological connectedness is inextricably intertwined with the value of self-regarding choice.

\section{Psychological Connectedness and Long-Term Decision-Making}

Although it is widely agreed that respect for self-regarding choices made under certain conditions (often referred to as "competent" or "autonomous" choice) is a vital or even the preeminent ethical value in medicine (Faden and Beauchamp 1986; Gillon 2003; Taylor 2009), there is sometimes limited reflection about just why it is that we value making our own choices so much. In order to understand the link between self-regarding choice and psychological connectedness, 
we will need to delve into this. A useful tool here will be Scanlon's account of the reasons we have to value making our own choices (1998). Although Scanlon presents this theory in a rather different context, we see similar concerns echoed in the literature on medical ethics. Scanlon suggests that there are three reasons that most of us have to value making our own choices, under the right conditions:

Instrumental Value: The most obvious reason that we generally have to value making our own choices is because this has instrumental value to us - making our own choices often appears to be the best way of achieving our own ends or goals, whatever they are. Scanlon gives the example of choosing what to eat at a restaurant. Given my own knowledge of my tastes and values, I might believe that choosing for myself is the best means of achieving my end of enjoying a satisfying meal (or whichever other end I wish to pursue in making a choice). Whether making my own choice does indeed present the best means to achieving this end, however, is clearly dependent on circumstance. If I cannot read the language that the menu is written in, or my capacities for discernment are clouded by hunger, I might not be in a good position to make this choice. The instrumental value of my choice might be improved by additional information, or attempts to mitigate influence affecting my judgment. Alternatively, it might turn out that someone else is in a better position to make the choice that best allows me to achieve my own ends. The instrumental value of choice is often emphasised as a significant reason to value making our own choices in medical contexts (Buchanan and Brock 1989; Glover 1977), based, crucially for our purposes, on "the assumption that a competent person is the best judge of his or her own interests." (Buchanan and Brock 1989, 153). Some theorists argue that the value of autonomy in medical ethics is purely instrumental (Taylor 2009; Varelius 2006).

Representative V alue: Scanlon, however, lists two further types of non-instrumental reasons we typically have to value making our own choices. Sometimes, he suggests, we value making our own choices, even when they are not the best means of achieving our desired outcome, because of what our choices then express or represent. We might want to choose our own gift for our spouse, or the furnishings in our home, even if someone else could do a better job, because of what the choice represents - our tastes, for example, or what we value. We might also make and value choices for representative reasons in medical contexts (Buchanan and Brock 1989, 39; Glover 1977, 81).

Symbolic Value: The last reason to value making our own choices, as listed by Scanlon, is because the ability to make these choices carries a certain social weight. In situations in which people are 
normally expected to make their own choices, being denied this ability can be seen as reflecting a judgment that a person lacks "the standing normally accorded to an adult member of the society" (1998, 253). Being denied the ability to make these choices may be experienced as demeaning, showing insufficient respect for a person's capacities, competence or worth. It is this dimension which is most closely connected to professions that persons have a "right" or "authority" to make certain of their own choices (even when we know that others could choose better), particularly choices concerning how to dispose over one's body (Dworkin 1994; Feinberg 1986). Recognizing a person's authority to make these decisions is sometimes regarded as essential to recognizing the dignity and worth of persons (Darwall 2006). We see similar sentiments in medical ethics, reflected in a view of making one's own choices as a valuable way to exercise and exhibit the "capacities for deliberation, choice and action that normal humans possess" (Buchanan and Brock 1989, 38).

This is not necessarily an exhaustive account of all the reasons we might have to value making our own choices ${ }^{1}$, and these reasons, in practice, will often coexist and can be difficult to distinguish. ${ }^{2}$ However, this gives us a good basis upon which we can start to draw in concerns usually thought to belong to the philosophical field of personal identity. Theories of personal identity are often concerned with identifying just what is it that makes a person the same person over time. This is often referred to as the question of persistence or reidentification. It is this time dimension that invokes similar issues when it comes to self-regarding choice in medical ethics. We can make all sorts of self-regarding decisions in a medical context. Some of these decisions are relatively low-stakes or easily reversible (like deciding to take certain types of medications). But other decisions (like, for example, the decision to undergo an amputation) are high-stakes, and have a long-term impact. This means that when you make such a decision, you are making a decision which will have an impact on your distant-future self. You are making this decision on behalf of your distant-future self as well as your present self. This is even more clearly the case when you issue an advance directive - here, you are making a choice purely on behalf of your future self.

The instrumental value of choice, as we have seen, is based upon the idea that a patient has particular insight into his own tastes, preferences, values and interests, so that he is in a position

\footnotetext{
${ }^{1}$ Göran Duus-Otterström (2011) lists several additional potential categories of reasons, and it might be the case that certain people have their own idiosyncratic reasons for valuing choice.

${ }^{2}$ Considerations linked to the representative and symbolic value of choice are often conflated to a certain extent in the literature on medical ethics (see Buchanan and Brock 1989, 38-9; Glover 1977, 81). This is likely because the discussion is often framed in terms of discerning whether choices have value beyond the obvious instrumental dimension.
} 
to make self-regarding decisions with particularly high instrumental value, as long as he is making the decision under sufficiently good circumstances (with sufficient information, sufficiently free of controlling influences, etc.). When we are making decisions with long term impact, we need to add an additional condition here - in order for your decision to be sufficiently likely to have high instrumental value for your distant-future self, you might need to be sufficiently psychologically connected to your distant-future self, so that your insight into your interests also provides special insight into his interests. If there is a significant shift in one's psychological makeup in the interim, there may be reason to doubt that you are in the best position to make the choice that is likely to have the highest instrumental value. The balance might, in some cases, swing in the other direction, and suggest that instrumental value might best be pursued through having someone else make this decision, just as in cases where the circumstances under which you are making the choice cannot be made sufficiently good.

Similar remarks apply to choices with representative value - if you make a choice in order to express your commitment to something that you value, and later come to repudiate this value due to psychological changes, your choice will have negative representative value from the perspective of your future self - he will be likely to regret having made this decision in the past. The balance here is slightly different, because you need to make your own choice for it to have representative value - a choice made by someone else cannot express something about yourself. Someone else, that is, cannot make a choice on your behalf that has higher representative value. However, it is clear that when it comes to long-term decisions, and in the case of drastic personality change, the representative value of making your own choices may be diminished.

Such concerns do not affect the symbolic value of choice - tied to the right to make your own decisions regardless of outcome. I will make further comments about how the symbolic value of choice intertwines with considerations of personal identity in the subsequent section. From the above considerations, however, we can see that psychological connectedness is an important underpinning of some of the sources of the value of making high-impact, long term decisions, though psychological disruption may not affect all of the reasons we value choice. The importance of the instrumental and representative value of choice should not be underestimated: it is only through reference to these values that we can explain why informing a patient, or ensuring that she is free of controlling influence, is so important in medical ethics. These measures put the patient in circumstances which better allow her to align her actions with her goals, or the values she wants to express through her choice. 
This notion that certain psychological factors should remain stable over time is also not alien to medical ethics; in their influential accounts of competence to consent to treatment in medical ethics, both Dan Brock (1991) and Thomas Grisso and Paul Appelbaum (1998) maintain that high-stakes treatment decisions should be scutinised in order to ascertain that the beliefs and values underlying them are enduring. Though far from a perfect measure, the stability of beliefs and values underlying a treatment decision might provide the best indicator we have that these values will persist into the future, and thus that the treatment decision will continue to be wellregarded by the patient into the future. This, of course, is compromised in cases where we have reason to suspect that a disruption in psychological connectedness might ensue.

\section{A Metaphysical or Normative Commitment?}

In the previous section, you may have noticed that I avoided adopting an explicitly psychological picture of personal identity - I have assumed that although a disruption in psychological connectedness might diminish the value of making our own decisions, it still makes sense to talk about a single person existing prior to and after a personality shift that leads to a loss of these connections. In this section, I will connect what I have said in the previous section to the debate concerning different theories of personal identity. To draw this out, let's first take a step back to outline just what a psychological theory of personal identity is, and what its main competitors are. This will also lay the groundwork for my critique of bioethical work based on non-psychological theories in the subsequent sections.

The problem of personal identity I am focusing on here, as noted above, is the problem of reidentification or persistence - what allows us to say that someone is the same person at two different points in time, and, on the opposite side of the same coin, what type of changes can cause a person to cease to exist? Psychological or neo-Lockean theorists suggests that the key is psychological connections that endure over time. We are linked to our previous selves through memories of past experiences, actions motivated by past intentions, enduring beliefs, desires, values, and other psychological elements. If enough psychological connections exist between two people at two different points in time, we can say that they are the same person. Some theorists prefer to focus more on psychological continuity than connectedness (see Schechtman 2010) - it is not direct connections that are important in establishing identity through time, but rather an overlapping and unbroken chain of psychological connections, stretching through time like a rope, while some theorists think both relations are important (Parfit 1984). Either way, some sort of drastic shift in our psychological contents, a fundamental change in our values, beliefs, desires, created by, for example, a religious epiphany, deep brain stimulation, or dementia, might be 
enough to disrupt both psychological continuity and connectedness, leading us to say that the resulting person is not the same as the person who came before. The previous person has ceased to exist, and a new person has (perhaps) come into existence. Just how many psychological connections we need to establish continued identity is a matter of debate - some prefer to set the threshold quite high, requiring many enduring or overlapping connections, while others think that a lower threshold is preferable (Buchanan and Brock 1989). Such a theory is metaphysical in nature, it aims to tell us what the fundamental nature of persons is, what is it for a person to exist, or not to exist (see Nyholm 2018). But psychological theories of personal identity are also closely tied to practical concerns - this theory of personal identity, according to adherents, can tell us who to hold responsible for past crimes, or who is the appropriate object of prudential concern (Schechtman 2010).

The main competing metaphysical theory of personal identity argues that it is rather bodily continuity that is the key to personal identity - as long as you have the same body (or maybe a specific part of the body, such as the brain stem), you are the same person. Adherents to this type of theory are generally motivated by metaphysical rather than practical concerns - problems to do with picking out a single person over time (Williams 1957), or establishing how we are identical to the foetus from which we developed (Olson 1997). In fact, the most prominent contemporary advocates of biological continuity argue that it is purely metaphysical in nature that uncovering what we are at the most fundamental level, and the conditions for our persistence, does not have much to do with practical ethical questions - to address these, we still need to appeal to psychological continuity (Olson 1997, 69-71, DeGrazia 1999, 338-9).

A third popular theory of personal identity, which has been utilized extensively in recent work on medical ethics, particularly in the context of deep brain stimulation (see Baylis 2009; Jecker and Ko 2017; Nyholm and O'Neill 2016) is the narrative theory. This theory is not metaphysical in the sense of the other two - rather than focusing on what a person is at the most fundamental level, and how to reidentify a person at a later point in time, this theory asks how we can attribute actions, beliefs, values character traits and so on to a given person. The answer to this, according to narrative theorists, is that these traits are attributable to the person insofar as they are incorporated into an intelligible and coherent narrative that gives shape and meaning to the individual's life (Schechtman 1996). This theory is intended to account for practical concerns such us as when is it appropriate to attribute responsibility to someone. 
We can now turn to the connection between theories of personal identity and the value of choice. Although the instrumental value of choice is contingent on a person remaining sufficiently psychologically connected to her future self, so that she is in the best position to make decisions on behalf of her future self, this does not require any metaphysical commitment about what the self is on its most fundamental level. We could endorse any of the theories of personal identity outlined above, while still maintaining that psychological connectedness is important for this specific purpose - it is a condition of ensuring that decisions are sufficiently likely to have sufficient instrumental and representative value. Let's imagine, for example, that we are biological continuity theorists - we simply accept that persons always retain their identity throughout the entire course of their bodily lives, and that no psychological change could possibly disrupt continued identity. This does not give us a reason to expect that a decision will have instrumental value for your future self in the absence of psychological connectedness, or that you are necessarily in a particularly good position to make a decision for your future self.

At the other end of the spectrum, we might be sceptics about personal identity, believing that there simply is no metaphysical entity that exists through time, and remains the same (see Parfit 1984), and thus that we never retain identity through time. This does not undermine the fact that a person who is very psychologically similar to a person in the future will be well placed to make decisions with high instrumental value for this future person. The instrumental value of choice comes apart from our metaphysical commitments about personal identity. It is rather a normative commitment - a significant reason that we value making our own decisions is because this has instrumental value to us, but we can only expect that choices will have this instrumental value if we are psychologically connected to the person who made the decision. The importance of psychological connectedness comes from the fact that it underpins something we value - the instrumental value of choice.

The representative value of choice is more complicated - for a choice to have representative value, you need to have made it, not someone else who is psychologically similar to you. But a metaphysical theory of personal identity does not seem to help much in whether you can or will regard a past decision as expressing or representing something about yourself - it does not seem to be the case, for example, that you will necessarily regard the choice as your own if the biological continuity theory of personal identity is the "true" metaphysical theory that best describes the fundamental nature of what exists in the world, and you share a body with the person who made the choice. Perhaps the narrative theory of identity is of some use in approaching this - as long as you regard a past choice as your own, you attribute it to yourself, 
and it can continue to have representative value for you. Despite these complications, however, we can still recognise that choices are likely to have diminished representative value if you undergo a shift in what you value and believe - the attributes that you wanted to express in your decision might be ones that you later come to feel indifferent about or even repudiate. So psychological connectedness is certainly an important underpinning of this value of choice, and this aspect can be recognised while remaining neutral about what the persistence conditions of persons are (although it might turn out that the representative value of choice can be diminished or nullified in other ways, if you, for whatever reason, can no longer regard a past choice as your own).

To settle the question of symbolic value, on the other hand, it does seem like we will need a metaphysical answer to the question of persistence. If we see symbolic value as linked to the principle that you have a right to decide for yourself, we need to know whether a future person is you to know whether you have the right to decide for this person on these grounds. ${ }^{3}$ If we imagine, for example, that the "true" theory of the self is based on psychological continuity, then it would be a misapplication of this principle to make decisions on behalf of a future person who has undergone drastic psychological change, and is thus no longer you. Scepticism about personal identity will also have serious ramifications here - if the boundaries of the self do not exist and can't be clearly defined, it might be the case that this principle does not have applicability through time.

\section{The Source of Value: Biological Continuity and Advance Directives}

With this groundwork in place, we are now in a position to turn to problems with work in medical ethics that rests on problematic assumptions about personal identity. As we've seen in the previous section, we can recognise that an underlying assumption of psychological connectedness is important in ensuring that choices have instrumental and representative value, no matter what position we take on personal identity. However, problems can arise when bioethicists endorse a theory of personal identity which is unable to recognise or accommodate the importance of psychological connectedness.

Take, for example, Sabine Müller, Merlin Bittlinger and Henrik Walter's work on personal identity and potentially personality-altering neurosurgeries (2017). Müller and colleagues are concerned about the role that metaphysical ideas about personal identity play in bioethical

\footnotetext{
${ }^{3}$ On these grounds is important here; Allen Buchanan and Dan Brock mount a compelling argument that advance directives can be justified after significant personality change (that they take to sever identity) on other grounds (1989, 163-5), which we will explore below.
} 
discussions. They are particularly concerned that invoking certain theories of personal identity (mainly psychological, but also narrative theories) might be used to undermine advance directives, which they take to be of central importance in ensuring that patients have the "right" to "exercise their autonomy" $(2017,300)$. They instead endorse a biological continuity-based theory of personal identity, not for metaphysical reasons, but because this theory guarantees identity between a person making the decision and a person at a later stage who has lost many of their previous capacities, someone, for example, with end-stage dementia, or who is in a coma, ensuring that an advance directive will retain its moral and legal force. They argue that we should keep discussion of metaphysical concerns about personal identity, particularly discussion concerning psychological continuity or connectedness, out of bioethical discussions altogether. Ultimately, they contend, "the application of psychological continuity theories of personal identity on these neuroethical issues - particularly adapted versions of Parfit's theory and its metaphysical implications - is of limited use.” $(2017,308)$.

Müller and colleagues' desire to retain the authority of advance directives is certainly understandable. But the route which they take to defend advance directives misses an important dimension of the problem. In order to see why this is, it is first important to reiterate that concerns about psychological connectedness need not be purely metaphysical. Although they echo the metaphysical debate about personal identity, the grounds upon which I have invoked psychological connectedness are purely normative. We value making our own decisions, in part, because we believe that we can decide in a way that will have the most instrumental and representative value for ourselves. In cases where drastic personality change greatly affects the things that we value, we can no longer make this assumption. This may change the balance of values in these cases, potentially weakening or undermining the reasons we value having advance directives in the first place. Acknowledging this has nothing to do with metaphysical concerns.

In order to illustrate this, let's turn to a difficult case considered by bioethicists Allen Buchanan and Dan Brock, in their discussion of personal identity and advance directives. Buchanan and Brock accept, for the sake of argument, a psychological continuity-based concept of personal identity, and consider the consequences for advance directives. They argue that the degree of psychological continuity required for continued identity should be quite low. A patient with severe dementia, severe brain damage, or a patient in a coma will fall below the threshold required for continued identity, but someone with personality change resulting from moderate dementia or brain damage, for example, should still be considered to be the same person. They imagine a case in which, according to this picture, personal identity is retained: 
An apparently valid advance directive specifies that no life-sustaining treatments, including antibiotics, are to be used on the individual if he or she suffers a loss of cognitive function. The patient does suffer a serious loss of cognitive function due to a discrete neurological injury, such as a stroke. He or she is now a moderately mentally handicapped person, but clearly a person - and indeed the same person - nonetheless. Moreover, the patient is quite happy, and wants to live. Then the patient develops a life-threatening pneumonia. Following the advance directive will result in the easily avoidable death of a happy and reasonably healthy, although mentally handicapped person. Suppose, also, that he or she is judged not to be competent to rescind the advance directive. $(1989,188-9)$.

This case, they argue, presents a challenge for the absolute authority of advance directives, and makes the exercise of paternalism in this case tempting. I believe the picture of the value of selfregarding choice I have given above can explain our hesitance in enforcing an advance directive under these circumstances. The changes in the patient's psychological make-up means that at the time she issued the advance directive, she was not in a good position to imagine which choices would have the most instrumental value for her in her current state. Perhaps she could not imagine that she could possibly be happy, or have a life worth continuing, in this state. Now we are faced with a patient who is clearly happy. The advance directive recommends a course of action which seems so clearly to be against her own happiness and interests, subjectively conceived. It is this, I believe, which accounts for our reluctance in this case.

Drastic personality change and subsequent low instrumental value of the initial choice might weaken the moral authority of an advance directive. This is the case even if we assume, as do Müller and colleagues (and Buchanan and Brock), that the woman who issued the advance directive and the patient with pneumonia are the same person. Whether or not one is the same person as the person who issues the advance directive does not necessarily settle the question of whether the advance directive should be respected - the value and moral authority of the advance directive rests, at least in part, on its presumed instrumental value, which in turn rests on an assumption of a sufficient degree of psychological connectedness. We cannot eschew issues of psychological connectedness even if we put all metaphysical discussion to one side and assume that identity is retained. ${ }^{4}$

\footnotetext{
${ }^{4}$ There might, however, be pragmatic reasons for respecting the advance directive in these circumstances anyway attempts to institute limits on advance directives where psychological connectedness is significantly weakened might lead to them being ignored on an (unjustifiably) wider scale in favour of medical paternalism (Buchanan 1988). This does not undermine the point that we cannot understand an important source of the value of advance directives, and thus the reason that we regard them as having moral authority, without considering psychological connectedness and the instrumental value of choice.
} 
What then, of the most extreme cases considered by Müller and colleagues; cases, for example, in which the patient is in an irreversible coma? The problem here is not that the patient may have changed in ways that may lead to her no longer regarding her previous decisions as prudent or conducive to her happiness and interests, but that she has lost the ability to consider these choices at all. This presents us with a rather different situation to that considered above. Some (psychological continuity) theorists see this problem not so much as involving the destruction of one person and the creation of another, but rather a loss of personhood altogether. Many advance directives will involve circumstances such as these. How then, should we approach these cases? Is there any reason to recognise their authority without endorsing a biological-continuitybased picture of personal identity?

Buchanan and Brock give us an alternative means of approaching these problems. As we have seen, they assume a psychological theory of personal identity, with a low threshold of continuity required to retain identity. It is an unavoidable consequence of their theory that personhood is severed in these extreme cases. However, they do not take this to undermine the validity of advance directives. Just as we generally take a person to have interests surviving death (they might have an interest in taking care of their family, for example, that we honour after death through executing their will), they argue, we can take a person to have interests surviving permanent unconsciousness, or severe brain damage that severs identity (1989,163-4). These include what will happen to the body that they used to inhabit, what kind of resources should be expended to keep it alive and at what emotional and financial cost to their family, and so on. Such interests may need to be weighed against the current "experiential interests" of the person in a severely brain damaged state, for example, but they can and should play a role in what happens to this person.

Müller and colleagues' call to keep abstract metaphysical concerns about psychological continuity and connectedness out of bioethical discussion misses an important dimension of why we value making our own choices and what may cause this value to be diminished. These concerns about psychological connectedness are inextricable from the value that we assign to making our own choices, if we believe that instrumental value is an important source of the value of choice. In other words, we cannot understand the value of advance directives independently of psychological connectedness over time. The assumption of psychological connectedness over time plays a key role in why we think "the exercise of future-directed personal autonomy" (Müller, Bittlinger and Walter 2017, 303) is important, and should override other concerns (such as our view of what is in the person's best interests). Furthermore, the imperative to respect 
advance directives in extreme cases can be justified on other grounds, without maintaining that identity must be regarded as inhering in the continuity of the body.

But a defender of Müller and colleagues might argue that I have missed the point here - that when they talk about autonomy, they do not see the importance of this as grounded in instrumental concerns or interests. After all, they talk about a "right" to exercise one's autonomy $(2017,300)$. Might it be the case, then, that they see the importance of autonomy as rooted in its symbolic value - that we should simply be allowed to make self-regarding decisions, and that this has nothing to do with their instrumental value? As we have seen above, this route creates another set of problems for Müller and colleagues. Namely, we need to know that a person is the same person as the person who issued an advance directive, before we know that it is appropriate to enact this advance directive on the grounds that the person has a right to decide for himself. We cannot avoid metaphysical concerns in working out how this right can legitimately be exercised. It is question begging to assume that this right can be exercised because a person has the same body as a previous person - in order to know if the "right to decide for yourself" applies, we must first establish that the decision maker and the person for whom the decision is being made are indeed the same person.

Prominent biological continuity theorist Eric Olson goes even further than this, arguing that even though biological continuity accounts for what we are at the most fundamental level and is thus the correct metaphysical theory of personal identity, this cannot be used to make any ethical inferences (1997, 69-71; see also Schechtman 2010, 276-7; DeGrazia 1999, 338-9). That is, even if we do assume that we are our bodies, additional argument might be required to claim that we have a right to decide for ourselves in this sense. Again, Buchanan and Brock's suggestion provides us with a more promising way of maintaining that you should be able to make decisions on behalf of your future body, whether you share identity with this body or not.

\section{Capturing What We Value: Narrative Identity and Deep Brain Stimulation}

A second, more popular strand of argument that runs into problems is based on a narrative picture of identity, which is often used to make sense of the personality changes resulting from deep brain stimulation, and how they are regarded and approached by the patient (see e.g. Baylis 2009; Blustein 1999; Jecker and Ko 2017; Nyholm and O’Neill 2016). Where the previous section dealt with issues that arise after a disruption in psychological connectedness has already taken place, this section will deal with making decisions about potential psychological changes that are yet to come. How do we understand what concerns the patient in making these decisions, and 
put forward a picture that captures what he values, and the basis upon which he makes these decisions? I will argue here that we can only make sense of what the patient values when making decisions involving personality change if we appeal to psychological connectedness - in making this decision, the patient aims to retain certain psychological connections, and it is the disruption of these connections that concerns the patient when he expresses concern about personality alterations.

Nancy Jecker and Andrew Ko (2017) provide us with a good example of a defence of a narrative approach to identity as a means to understanding the personality changes brought on by deep brain stimulation. Jecker and Ko want to work out which changes might be experienced as problematic, and get to the heart of what concerns patients are expressing when they are worried that personality changes will mean that they don't 'survive' the intervention - that they will become, in some sense, a different person. As we have seen above, narrative accounts of identity are not metaphysical - they are concerned with what traits are properly attributable to a person. Jecker and Ko see this as a strength of narrative identity in this context - they want to capture and focus on what matters to the patient, rather than the metaphysical conditions for persistence. They suggest that insofar as psychological changes can be incorporated into a patient's "the selftold story of his or her life" $(2017,160)$, these new traits can be attributed to this person, and this captures what patients mean by survival in this context. As long as these changes can be weaved into the patient's own narrative, the patient need not fear that she will become a different person. This understanding of the self, Jecker and Ko argue, provides a good basis for making these medical decisions.

Narrative identity, as a guide for decision making, comes apart from theories that emphasize the importance of one's stable values, beliefs, and other psychological traits. Though these factors might form important reference points in one's narrative, narrative theorists emphasize that making a decision that fits your narrative comes apart from deciding on the basis of your settled values and beliefs (Blustein 1999). How then, do we decide which changes might be incorporated into our own life story? There are certain constraints that narrative theorists place on the construction of a narrative - some emphasize "correctness" (Jecker and Ko 2017) or a "reality constraint" (Schechtman 1996), the requirement that narratives must not contradict "basic, wellestablished, matters of observable fact" (Schechtman 1996, 121). Some theorists also contend that a narrative needs to be coherent to a certain degree, although it's not quite clear how stringent this standard should be (Blustein 1999). 
So, there are some constraints on which of our possible decisions might fit our narrative. But this doesn't give us much guidance concerning which decisions we should make. Narrative identity is compatible with drastic change (Baylis 2009), and several alternatives are likely to fit a possible coherent narrative equally well when we are faced with a choice (Kuczewski 1999). Intelligible and coherent narratives can even be crafted around fundamental changes that one strongly repudiates, or that are caused by oppressive social structures (Schechtman 2003). In short, a narrative picture as identity as the basis for making high-stakes decisions does not provide us with an indication of which changes will or could be incorporated seamlessly into the patient's narrative, and which might be experienced as troubling and disruptive to one's identity. ${ }^{5}$

Understanding psychological connectedness as the underlying basis upon which these decisions are made, on the other hand, does give us guidance in making these decisions, and is centred around what is most important to the patient. This picture suggests that interventions might be regarded as problematic in this way if they disrupt our settled, stable values, beliefs and other psychological elements and cannot be endorsed on the basis of our existing subjective motivational set. It should not be thought that psychological connectedness requires a static personality, so that any changes should be seen as problematic. A patient, for example, might value spontaneity, but have trouble acting in a spontaneous manner. A personality altering intervention that (as a foreseeable side-effect) increases spontaneity is likely to be welcomed by this patient as in line with his values. Because the personality change will be connected to the existing values of the patient in this way, the personality change will be seen as having, and will continue to have, high instrumental and representative value for the patient - the choice will allow the patient to pursue what he values, and to better express this value through his conduct. Such a change is likely to be regarded by the patient as increasing his authenticity - as bringing his conduct more into line with what he values and desires. If the patient thinks spontaneity is a character flaw, on the other hand, he might experience such a change as problematic, unwanted, and disruptive to his identity (see Nyholm and O’Neill 2016).

If we recognize psychological connectedness as a basis for making valued and valuable decisions, we understand the fear of 'not surviving' a personality altering procedure as a fear that the deeply held values, beliefs and desires that form the core of a patient's personality will be replaced by others, and will lose the ability to motivate him (see Schechtman 2003). Change is compatible with this picture, as long as changes are concordant with or endorsable on the basis of these

\footnotetext{
${ }^{5}$ Michael Kühler makes a similar point about narrative identity in the context of surrogate decision making in his paper in this volume.
} 
traits, establishing connections that stretch through time. Such a picture gives us a basis for making these decisions in a way that captures what is valuable, and what is of concern to the patient, and thus gives us guidance concerning what we need to communicate to the patient, and how to understand and address the fear of not surviving personality change.

Establishing the importance of psychological connectedness as an underlying basis for making decisions of this type does not require a metaphysical commitment - like Jecker and Ko, I aim here to capture what concerns the patient has when he talks about survival, rather than making a metaphysical judgment about when we should say the patient has or has not survived. Thinking about this type of psychological connectedness when making these sorts of decisions can give us an indication of what consequences are likely to be welcomed by, and experienced as valuable to, the patient, and which are more likely to be repudiated. I believe that some accounts of narrative identity might be compatible with recognizing the importance of the type of psychological connectedness I am emphasizing here (see e.g. Nyholm and O’Neill 2016), just as accepting biological continuity as a metaphysical theory of personal identity can be compatible with recognising the importance of psychological connectedness when it comes to issues of practical and ethical importance. But insofar as either approach does not make room for the importance of psychological connectedness as an important source of value for long-term, high-stakes decision making, they are unable to capture what makes decisions valuable to the patient, and what is of concern to them when making these decisions.

\section{Conclusion}

Part of the source of value of making one's own decisions is instrumental - it provides a way of achieving one's goals or ends. Another source of value is representative - we want to express or represent what we value through our choices. Our choices only maintain this value over time if we remain psychologically connected to our former selves in certain ways - if our aims or values change, then the choice may no longer be valuable in these ways. This may make future-directed, self-regarding decisions less valuable in circumstances in which drastic personality change is imminent, and may weaken the moral authority of future-directed choice in these cases. This particularly applies to advance directives, where we are making a choice purely on behalf of our future self. There may be other good grounds upon which the authority of advance directives can be upheld, but we cannot identify the issues at stake here without delving into the sources of value of advance directives, and understanding the role that psychological connectedness has to play in this. Furthermore, reference to psychological connectedness allows us to understand what is of concern to the patient when she is facing potentially personality-altering interventions. It 
provides a picture underlying the patient's decisions that captures what she values - retaining certain central values and traits, while allowing for change that connects with existing values and priorities. Without underlying psychological connectedness, there is no sufficient basis upon which decisions can be made, and we cannot capture what the patient cares about in making decisions, distinguishing between changes that the patient is likely to welcome, and changes that she might find problematic or feel alienated from. To summarize; the patient values and aims for continued psychological connectedness in making decisions, and when these connections are severed, choices become less valuable, and their authority may be diminished. There is practical importance in exploring the interrelation between psychological connectedness and choice, with clear implications concerning how to understand and value self-regarding decisions in medical ethics, which comes apart from an abstract metaphysical debate about personal identity.

\section{References}

Baylis, Françoise. 2009. "“I am who I am”: On the Perceived Threats to Personal Identity from Deep Brain Stimulation.” Neuroethics 6(3): 513-526.

Blustein, Jeffrey. 1999. "Choosing for Others as Continuing a Life Story: The Problem of Personal Identity Revisited.” Journal of Law, Medicine and Ethics 27(1): 20-31.

Buchanan, Allen. 1988. “Advance Directives and the Personal Identity Problem.” Philosophy and Public Affairs 17(4): 277-302.

Buchanan, Allen, and Dan Brock. 1989. Deciding for Others: The Ethics of Surrogate Decision Making. Cambridge: Cambridge University Press.

Brock, Dan. 1991. “Decisionmaking competence and risk." Bioethics 5(2): 105-112.

Darwall, Stephen. 2006. "The Value of Autonomy and Autonomy of the Will.” Ethics 116(2), 263-84.

DeGrazia, David. 1999. “Advance Directives, Euthanasia, and the Someone Else Problem.” Bioethics 13(5): 373-391.

Duus-Otterström, Göran. 2011. "Freedom of the Will and the Value of Choice." Social Theory and Practice 37(2): 256-84.

Dworkin, Gerald. 1994. "Markets and Morals: The Case for Organ sales.” In Morality, Harm and the Law, edited by Gerald Dworkin, 155-161. Boulder: Westview Press.

Faden, Ruth and Tom Beauchamp. 1986. A History and Theory of Informed Consent. Oxford: Oxford University Press. 
Feinberg, Joel. 1986. The Moral Limits of the Criminal Law Volume 3: Harm to Self. New York: Oxford University Press.

Gillon, Raanan. 2003. "Ethics Needs Principles_-Four Can Encompass the Rest—and Respect for Autonomy Should be "First Among Equals"." Journal of Medical Ethics 29(5): 307-312.

Glover, Jonathan. 1977. Causing Death and Saving Lives. London: Penguin Books.

Grisso, Thomas, and Paul Appelbaum. 1998. Assessing Competence to Consent to Treatment: A Guide for Physicians and Other Health Professionals. New York: Oxford University Press.

Jecker, Nancy, and Andrew Ko. 2017. "Is that the Same Person? The Problem of Identity Following Neurosurgical Procedures.” AJOB Neuroscience 8(3): 2-29.

Kuczewski, Mark. 1999. "Commentary: Narrative Views of Personal Identity and Substituted Judgment in Surrogate Decision Making." Journal of Law, Medicine and Etbics 27(1): 32-36.

McInerney, Peter. 1990. "Does a Fetus Already Have a Future-Like-Ours?” Journal of Philosophy 87(5): 264-268.

Müller, Sabine, Merlin Bittlinger, and Henrik Walter. 2017. "Threats to Neurosurgical Patients Posed by the Personal Identity Debate.” Neuroethics 10(2): 299-310.

Nyholm, Sven. 2018. "Is the Personal Identity Debate a "Threat" to Neurosurgical Patients? A Reply to Müller et al.” Neuroethics 11(2): 229-235.

Nyholm, Sven, and Elizabeth O’Neill. 2016. Deep Brain Stimulation, Continuity Over Time, and the True Self. Cambridge Quarterly of Healthcare Ethics 25(4): 647-58.

Oderberg, David. 1997. "Modal Properties, Moral Status and Identity." Philosophy and Public Affairs 26(3): 259-298.

Olson, Eric. 1997. The Human Animal: Personal Identity without Psychology. Oxford: Oxford University Press.

Parfit, Derek. 1984. Reasons and Persons. Oxford: Oxford University Press.

Scanlon, T. M. 1998. What We Owe to Each Other. Cambridge: Harvard University Press.

Schechtman, Marya. 1996. The Constitution of Selves. Ithaca: Cornell University Press.

Schechtman, Marya. 2003. “Empathic Access: The Missing Ingredient in Personal Identity.” In Personal Identity, edited by Raymond Martin and John Barresi, 238-59. Oxford: Blackwell. 
Schechtman, Marya. 2010. "Personhood and the Practical." Theoretical Medicine and Bioethics 31(4): 271-283.

Taylor, James. 2009. Practical Autonomy and Bioethics. New York: Routledge.

Varelius, Jukka. 2006. "The Value of Autonomy in Medical Ethics." Medicine, Health Care and Philosophy 9(3): 377-388.

Warren, Mary Anne. 1977. "Do Potential People Have Moral Rights?” Canadian Journal of Philosophy 7(2): 275-289.

Williams, Bernard. 1957. "Personal Identity and Individuation." Proceedings of the Aristotelian Society 57: 229-252. 